\title{
R\&D Outsourcing Contract for the Unverified Value of Tacit Knowledge Sharing
}

\author{
Han Song, YuQing. Liu, Ying Dai, Jing Zhu \\ Chongqing University of Technology (China)
}

songhan_0@126.com, buangfang@,cqut.edu.cn,_daiving@,cqut.edu.cn,songhan@,cqut.edu.cn

Received: May 2015

Accepted: October 2015

\section{Abstract:}

Purpose: The purpose of this paper is to provide a $R \& D$ outsourcing contract design framework to incent R\&D outsourcing service providers sharing tacit knowledge.

Design/methodology/approach: The author uses the principal-agent theory to builds multitask principal-agent model which focuses on two cases. One case is that the effort costs of explicit and tacit knowledge sharing are complementary, while another is the effort costs are substitutable.

Findings: When the costs of explicit and tacit knowledge sharing are complementary, the buyer can increase the incentive coefficient of explicit knowledge sharing to stimulate tacit knowledge sharing. This motive method not only stimulates tacit knowledge sharing, but also will further stimulate the effort levels of explicit knowledge sharing. Moreover, the multitask R\&D outsourcing contract can motivate the effort of explicit knowledge sharing to achieve system optimization, but it fails to motivate the effort of tacit knowledge sharing to achieve system optimization.

Research limitations/implications: In this paper we only consider that the outsourcing relationship is short-term, so the multitask $\mathrm{R} \& \mathrm{D}$ outsourcing contract is formal. In fact, the outsourcing relationship may be long-term, and the multitask R\&D outsourcing contract will be informal. 
Practical implications: Our study provides a theoretical model for formulating an effective $\mathrm{R} \& \mathrm{D}$ outsourcing contract and promoting the transfer of tacit knowledge sharing.

Originality/value: The paper extends prior literature by designing multitask R\&D outsourcing contract in order to share the tacit knowledge. We not only consider the cost of substitution relationship between tacit knowledge and explicit knowledge, but also consider the cost of complementary relationship.

Keywords: R\&D outsourcing, knowledge sharing, tacit knowledge value, principal-agent, incentive contract

\section{Introduction}

For acquiring external knowledge quickly, the enterprises may outsource R\&D business to professional service providers (SP) (Han \& Bae, 2014). Knowledge can be divided into explicit knowledge and tacit knowledge (Mulkay, 2014). Most of explicit knowledge in R\&D outsourcing is expressed in the form of reports, patents software and so on. Its value can be verified by third-party organizations, such as review panel, Patent Office and Software Testing Center. In contrast, tacit knowledge can be transmitted and shared between SP and enterprises through communication, but its value cannot be verified like explicit knowledge (Suppiah \& Sandhu, 2011).

Zhou, Qu and Joyce (2012) thought that R\&D outsourcing should be discussed within the context of risk management theory. Based on the British Petroleum (BP) neural network, they built a risk-warning model which can examine and manage R\&D outsourcing risks. Bals, Kneis, Lemke and Pedersen (2013) emphasized that managers must understand, which R\&D activities can be outsourced and which need to stay in-house in order to ensure competitiveness. R\&D outsourcing may result in intellectual property infringement. Buss and Peukert (2015) discussed how the intellectual property infringement caused by R\&D outsourcing fosters technology diffusion and affects R\&D Outsourcing decision.

The outsourcing contract stipulates the rights and obligations of the buyer and contractors (Qi \& Chau, 2012). At present, there are much literature which concern outsourcing contract. For example, Aksin, De Véricourt and Karaesmen (2008) studied a call center outsourcing contract analysis and choice problem, which faced by a contractor and a service provider, who receives an uncertain call volume over multiple periods and is considering outsourcing all or part of these calls to a contractor. Yao, Jiang, Young and Talluri (2010) studied three common outsourcing contracts (fixed-price, cost-plus, and gain-sharing) and address issues, when to outsource and which contracts to select. Based on analyzing risk factors of producer services outsourcing, Cai, Kai and Zou (2011) built the producer services outsourcing contract by 
designing the incentive and monitoring mechanism. Zhu, Li and Zheng (2014) built a game theoretic model, which is used to design the optimal contracts between the buyer and the supplier under two types of information scenario. Gershman and Kuznetsova (2013) thought that efficient contracts should guarantee not only fair rewards but also competitive selection in order to prevent an excessive inflow of the workforce from other sectors of the economy.

The existing outsourcing contracts may focus on the transmission and sharing of explicit knowledge whose value can be verified, and ignore the unverified value of tacit knowledge. It leads to the insufficient sharing of tacit knowledge in R\&D outsourcing. However, a lot of tacit knowledge is the key for employers to make technological breakthrough (Martínez-Noya \& García-Canal, 2011; Kloyer \& Scholderer, 2012). Therefore, how to design an effective contract to share the tacit knowledge whose value is unverified and to acquire explicit knowledge is an issue that must be considered when the buyer formulates the R\&D outsourcing contracts (Quinn \& Strategy, 2013).

The existing $R \& D$ outsourcing contract researches concern the choice of $R \& D$ outsourcing contracts, the design and optimization of contracts parameters and so on. For example, Jain, Hasija and Popescu (2013) analysed and compared the effectiveness of fixed-price contracts and cost-plus contracts in terms of the choice of R\&D outsourcing contracts from many aspects, such as ex ante information asymmetry and ex post information asymmetry, friction in renegotiation and project uncertainty. Aiming at parameter selection in R\&D outsourcing contract, Ulset (1996) researched the outsourcing cases of 80 enterprises. It has achieved the effective mechanism of managing the R\&D outsourcing contracts and puts forward the method to choose the parameters in R\&D outsourcing contract. Aiming at researching the behavior that service providers disclose customers' knowledge in outsourcing, Lai, Riezman and Wang (2009) built the multi-period game model and optimizes the excitation parameters of R\&D outsourcing contract. It has helped control the possible disclosure of service providers. Suppiah and Sandhu (2011) designed a structural questionnaire and carried out a field survey on the willingness of tacit knowledge sharing among 216 knowledge employees. The results showed that different types of psychological contracts have different influences on employees' willingness of tacit knowledge sharing.

All the literature above introduce the consequence of knowledge sharing, namely the value of knowledge, into contract when choosing R\&D outsourcing contracts, designing and optimizing parameters, thereby linking the income of service providers with the value of knowledge to stimulate service providers to share knowledge (Pashupatimath \& Ramakrishna, 2015). Explicit knowledge can be verified by the third-party organizations and be regarded as an object of contracts. Therefore, the knowledge-sharing of service providers above, which is stimulated by the connection between the income of service providers and the value of knowledge in R\&D outsourcing contract, has some effects in stimulating explicit knowledge-sharing. Nevertheless, the value of tacit knowledge cannot be verified by the third-party organizations, thus the R\&D 
outsourcing contract seems so feeble in stimulating tacit knowledge sharing (Kultti \& Takalo, 2000). There are a lot of researches on inter-organizational tacit knowledge sharing (Cheng, 2011; Soekijad \& Andriessen, 2003), which research strategic alliances, virtual team and supply chain separately, but there are few researches about tacit knowledge sharing in R\&D outsourcing contracts. However, they focus on the problem of tacit knowledge sharing and ignore the fact that explicit knowledge sharing and tacit knowledge sharing should complement each other. For this problem, Song, Zhang and Li (2012) built a multitask principal-agent model for explicit knowledge sharing and tacit knowledge sharing. It emphatically analyzes whether the stimulation of explicit knowledge sharing will influence the stimulation of tacit knowledge sharing or not, and in what manner. But it is regrettable that the author does not provide further analysis about how to realize the stimulation of explicit and tacit knowledge sharing when the value of tacit knowledge cannot be verified.

Given this, this paper builds a multitask principal-agent model for explicit and tacit knowledge sharing stimulation in the case of unverified value of tacit knowledge, and analyzes the effect of formal contract and informal contract on the incentive of explicit and tacit knowledge sharing in R\&D outsourcing contract in short-term as well as in long-term, so as to provide a theoretical model for formulating an effective R\&D outsourcing contract and promoting the transfer of explicit and tacit knowledge sharing.

\section{The Model}

Consider a risk neutral buyer outsourcing R\&D project to a risk neutral SP. Generally speaking, service providers create and innovate knowledge technology by investing knowledge, technology and human capital in R\&D, most researches use the degree of service provider's hardworking to describe the R\&D's investment of service providers quantitatively. For that reason, this paper follows this method, but it divides effort into two types according to the characteristics of knowledge, which includes explicit and tacit knowledge. One is $e_{1}$, the level of efforts made in sharing explicit knowledge, which can be expressed by coding and whose value can be verified by the third-party organizations; the other is $e_{2}$, the level of efforts made in sharing tacit knowledge, which cannot be expressed by coding and whose value cannot be verified by the third-party organizations, wherein $0 \leq e_{1} \leq 1,0 \leq e_{2} \leq 1$. Suppose further that the

cost function of these two efforts is $C\left(e_{1}, e_{2}\right)=\frac{1}{2}\left(k_{1} e_{1}^{2}+k_{2} e_{2}^{2}+s e_{1} e_{2}\right)$, wherein $k_{1}$ and $k_{2}$ are independent quadratic cost coefficients for the two efforts respectively, $s$ is the cost correlation coefficient of the two efforts. The cost function above has the general features of convex function, which cost and marginal cost increase progressively. If $s<0$, it means that the increase of one effort can lead to the decrease of the marginal cost of the other effort. In the 
same way, if $s>0$, it means that the increase of one effort can lead to the increase of the marginal cost of the other effort.

Where $e_{1}$ is the input (efforts level) of service providers in sharing explicit knowledge, $e_{2}$ is the efforts level of service providers in sharing tacit knowledge, $k_{1}$ and $k_{2}$ are independent cost coefficient for the two efforts respectively, $s$ is the cost correlation coefficient of the two efforts. The cost function above has the general features of convex function, which cost and marginal cost increase progressively. On the other hand, the cross partial derivative of two efforts' cost function is $\frac{\partial^{2} C\left(e_{1}, e_{2}\right)}{\partial e_{1} \partial e_{2}}=\frac{1}{2} s$. if $s<0$, it means that the increase of one effort can lead to the decrease of the marginal cost of the other effort. In the same way, if $s>0$, it means that the increase of one effort can lead to the increase of the marginal cost of the other effort. Consequently, the cost correlation coefficient of two efforts $s$ shows the complementary or substitutional relationship between explicit and tacit knowledge. The value which the buyer can earn from explicit and tacit knowledge sharing is $\pi_{1}\left(e_{1}\right)=\lambda_{1} e_{1}, \pi_{2}=\lambda_{2} e_{2}$, where $\lambda_{1}$, $\lambda_{2}$ are the output coefficient. The value $\pi_{1}$ can be verified, but the value $\pi_{2}$ can be verified. As employers cannot observe the efforts of service providers, there is a moral hazard. The conventional method to solve this problem is offering incentive wage. This paper uses revenue sharing contract to stimulate service providers to work hard, and continues to use the linear revenuesharing contract. We assumes that the payment paid by buyer is $W=F+\beta_{1} \pi_{1}+\beta_{2} \pi_{2}$, wherein $F$ is the fixed-price of $R \& D$ outsourcing, $\beta_{1}$ and $\beta_{2}$ are the incentive coefficients of revenue sharing, which are produced by sharing explicit and tacit knowledge. The component $\beta_{2}$ is not enforced by the third parties such as courts since the outcome $\pi_{2}$ is unverifiable. Formal contract is a kind of promise, which is used for ex ante definition and ex post verification. Besides, it can be enforced by the third-party organizations (e.g. court). Under the formal R\&D outsourcing contracts, the buyer and service providers are playing a single-cycle game. The time series of the game is shown in Figure 1.

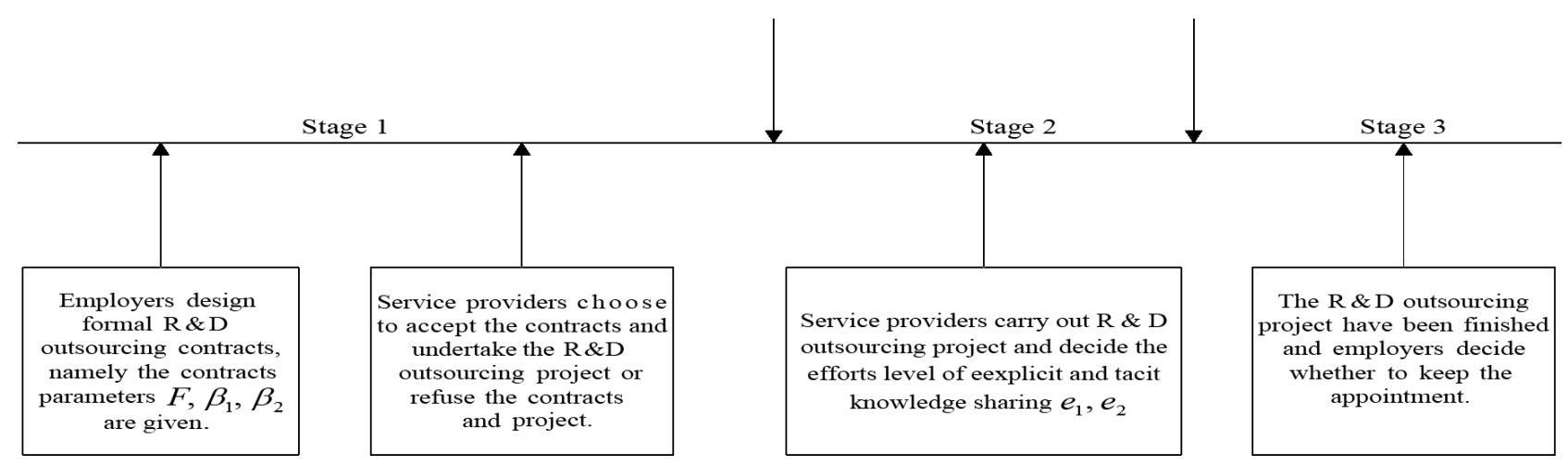

Figure 1. Time Series of the Game of Formal R\&D Outsourcing Contract 
According to the principle of reverse solving in a game, stage 3 should be firstly considered, that is, the buyer decide whether to fulfill the contracts or not. No matter the project succeeds or not, this fixed-price must be paid. Then, the achievements of explicit knowledge, as long as being verified by the third-party organizations, must be paid for by the buyer as stated in the contracts. If not, the buyer may be prosecuted and court will bring in an enforcement verdict. Compared with explicit knowledge, the value of tacit knowledge cannot be verified by court, so even though the buyer do not pay the money according to contracts, there is no risk in law. In this case, the buyer will choose to implement tacit knowledge sharing stimulation or not. If they do, $d=1$; if they do not, $d=0$. Therefore, the expected revenue of the buyer $R$ in the third stage is $R=\left(1-\beta_{1}\right) \lambda_{1} e_{1}+\left(1-d \beta_{2}\right) \lambda_{2} e_{2}-F$. Clearly, the revenue when $d=0$ is higher than that when $d=1$. For this reason, in the third stage of the game, the buyer who seeks to maximize their interests will choose $d=0$, which means they will not admit the value of tacit knowledge sharing. Then the revenue of the buyer can be expressed as

$$
R=\left(1-\beta_{1}\right) \lambda_{1} e_{1}+\lambda_{2} e_{2}-F
$$

In the second stage of the game, The SP decide how much efforts they will make to share explicit and tacit knowledge. According to the principle of complete rationality and reverse solving, in this stage, service providers can predict that the buyer will not pay for the value of tacit knowledge sharing in the third stage, namely they predict $d=0$. As a result, the expected revenue of service providers $r$ is

$$
r=F+\beta_{1} \lambda_{1} e_{1}-\frac{1}{2}\left(k_{1} e_{1}^{2}+k_{2} e_{2}^{2}+s e_{1} e_{2}\right)
$$

In the first stage of the game, the buyer designs the R\&D outsourcing contract. The contract must satisfy the incentive compatibility constraint and the participation constraint of principal-agent relationship. It can be described by the following optimization model P1 with inequality constraints:

$$
\begin{gathered}
\text { P1 } \max _{F, \beta_{1}} R=\left(1-\beta_{1}\right) \lambda_{1} e_{1}+\lambda_{2} e_{2}-F \\
\text { St } \frac{\partial r}{\partial e_{1}}=\beta_{1} \lambda_{1}-k_{1} e_{1}-\frac{1}{2} s e_{2}=0 \\
\frac{\partial r}{\partial e_{2}}=-k_{2} e_{2}-\frac{s e_{1}}{2}=0 \\
F+\beta_{1} \lambda_{1} e_{1}-\frac{1}{2}\left(k_{1} e_{1}^{2}+k_{2} e_{2}^{2}+s e_{1} e_{2}\right) \geq U
\end{gathered}
$$

In model P1, formula (3) is the target function of the buyer's revenue maximization, formula (4) and (5) are incentive compatibility constraints of service providers and formula (6) is 
participation constraint of service providers, which ensures that when service providers accept $R \& D$, their revenue is not less than reservation utility $U$. It should be noted that fixed-price $F$ is used to adjust the revenue of service providers in participation constraint. When the buyer's revenue reaches the maximum, the equation in participation constraint always holds. That is to say, the model above achieves the optimal condition $F=-\beta_{1} \lambda_{1} e_{1}+\frac{1}{2}\left(k_{1} e_{1}^{2}+k_{2} e_{2}^{2}+s e_{1} e_{2}\right)+U$.

\section{Model Solution}

When $s>0$, then there must be $\frac{\partial r}{\partial e_{2}}=-k_{2} e_{2}-\frac{s e_{1}}{2} \leq 0$. It means, when the two are mutually substitutable, the optimal effort levels of explicit and tacit knowledge sharing are $e_{1}=\frac{\beta_{1} \lambda_{1}}{k_{1}}$, $e_{2}=0$. The buyer's revenue is $R=\lambda_{1} \frac{\beta_{1} \lambda_{1}}{k_{1}}-\frac{1}{2} k_{1}\left(\frac{\beta_{1} \lambda_{1}}{k_{1}}\right)^{2}-U$. The buyer choose $\beta_{1}$ to maximize revenue, so the first order condition of their maximum revenue $R$ is $\frac{\partial R}{\partial \beta_{1}}=\frac{\lambda_{1}}{k_{1}}-k_{1}\left(\frac{\beta_{1} \lambda_{1}}{k_{1}}\right) \frac{\lambda_{1}}{k_{1}}=0$. So we can get $\beta_{1}^{*}=1$ into $e_{1}=\frac{\beta_{1} \lambda_{1}}{k_{1}}$, the optimal effort of sharing explicit knowledge is $e_{1}^{*}=\frac{\lambda_{1}}{k_{1}}$. Finally, get $e_{1}^{*}=\frac{\lambda_{1}}{k_{1}}$ into the formula of fixed-price $F=-\beta_{1} \lambda_{1} e_{1}+\frac{1}{2}\left(k_{1} e_{1}^{2}+k_{2} e_{2}^{2}+s e_{1} e_{2}\right)+U$ and the optimal fixed-price of R\&D outsourcing is $F^{*}=-\frac{\lambda_{1}^{2}}{2 k_{1}}+U$. At last, substitute all decision variables into the function of the buyer's revenue (1), and the maximum revenue of employer is $R^{*}=\frac{\lambda_{1}^{2}}{2 k_{1}}-U$

When $s>0$, we can get $e_{2}=-\frac{2 \beta_{1} \lambda_{1} s}{4 k_{1} k_{2}-s^{2}}$. From the assumption that the cost function is convex function, we can know that $4 k_{1} k_{2}-s^{2}>0$. Meanwhile, as $s<0$, it is obviously that $e_{1}=\frac{4 k_{2} \beta_{1} \lambda_{1}}{4 k_{1} k_{2}-s^{2}}>0, e_{2}=-\frac{2 \beta_{1} \lambda_{1} s}{4 k_{1} k_{2}-s^{2}}>0$. That is to say, the effort levels $e_{1}$ and $e_{2}$ are all greater than 0 . The sharing coefficients of optimal revenue are $\beta_{1}^{* *}=1-\frac{s}{2 k_{2}}, e_{1}^{* *}=\frac{2 \lambda_{1}\left(2 k_{2}-s\right)}{4 k_{1} k_{2}-s^{2}}$, 
$e_{2}^{* *}=-\frac{\lambda_{1} s\left(2 k_{2}-s\right)}{k_{2}\left(4 k_{1} k_{2}-s^{2}\right)}$, get $e_{1}^{* *}, e_{2}^{* * *}$ into the fixed-price function and simplify the function. The result is the optimal fixed-price $F^{* *}=-\frac{\lambda_{1}^{2}\left(2 k_{2}-s\right)^{2}}{2 k_{2}\left(4 k_{1} k_{2}-s^{2}\right)}+U, R^{* *}=\frac{\lambda_{1}^{2}\left(2 k_{2}-s\right)^{2}}{2 k_{2}\left(4 k_{1} k_{2}-s^{2}\right)}-U$.

The model solution shows, when the effort costs of explicit and tacit knowledge sharing are mutually substitutable, the multi-task incentive model of explicit and tacit knowledge sharing completely degrades into a single-task incentive model of explicit knowledge sharing. The reason for this is that the value which is produced by sharing tacit knowledge cannot be verified and employers will not pay for it. Meanwhile, under the condition of cost substitution, tacit knowledge sharing leads to cost increase of sharing explicit knowledge instead, so service providers will also not try to share tacit knowledge. when the effort costs of explicit and tacit knowledge sharing are substitutable, the revenue coefficient of tacit knowledge sharing stimulation is still meaningless. Employers will still not pay for the value of tacit knowledge sharing, but the model does not degrade into a single-task incentive model. Service providers will share not only explicit knowledge, but also tacit knowledge. We can find that both positive and negative $s$, namely the complementary and substitutional relation between the effort costs of explicit and tacit knowledge sharing, can affect the contract parameters given by employers and the ultimate profit of employers. Next, the paper will compare the influences of $+s$ and $-s$ on the final results for further management significance.

\section{Model Analysis}

(1) Comparison of the sharing coefficient of optimal revenue $\beta_{1}^{* *}-\beta_{1}^{*}=1-\frac{s}{2 k_{2}}-1=-\frac{s}{2 k_{2}}$. Note that $s<0$, so $\beta_{1}^{* *}-\beta_{1}^{*}=-\frac{s}{2 k_{2}}>0$. It means the sharing incentive coefficient of optimal revenue in the case of complementary relation is greater than the sharing coefficient of optimal revenue in case of substitutional relation.

(2) Comparison of the optimal effort levels of explicit and tacit knowledge sharing $e_{1}^{* *}-e_{1}^{*}=-\frac{s \lambda_{1}\left(2 k_{2}-s\right)}{\left(4 k_{1} k_{2}-s^{2}\right) k_{1}}, e_{2}^{* *}-e_{2}^{*}=-\frac{\lambda_{1} s\left(2 k_{2}-s\right)}{k_{2}\left(4 k_{1} k_{2}-s^{2}\right)}$. And then $e_{1}^{* * *}-e_{1}^{*}>0, e_{2}^{* * *}-e_{2}^{*}>0$, namely $e_{1}^{* *}>e_{1}^{*}, e_{2}^{* *}>e_{2}^{*}$. It means that the effort levels of explicit and tacit knowledge sharing in the case of complementary relation are all greater than those in the case of substitutional relation. 
(3) Comparison of the expected revenue of the buyer under two conditions $R^{* *}-R^{*}=-\frac{\lambda_{1}^{2}\left(2 k_{2}-s\right)^{2}}{2 k_{2}\left(4 k_{1} k_{2}-s^{2}\right)}-U-\frac{\lambda_{1}^{2}}{2 k_{1}}+U=\frac{\lambda_{1}^{2} s\left(\left(s-4 k_{2}\right) k_{1}+k_{2} s\right)}{2 k_{1} k_{2}\left(4 k_{1} k_{2}-s^{2}\right)}$. so $s<0$, And then $R^{* *}-R^{*}>0$, namely $R^{* *}>R^{*}$. It means that the expected revenue of the buyer in case of complementary relation is greater than that in case of substitutional relation.

(4) Comparison of the optimal fixed-price of R\&D outsourcing under two conditions $F^{* *}-F^{*}=-\frac{\lambda_{1}^{2} s\left(\left(s-4 k_{2}\right) k_{1}+k_{2} s\right)}{2 k_{1} k_{2}\left(4 k_{1} k_{2}-s^{2}\right)}$, then $F^{* *}-F^{*}<0$, namely $F^{* *}<F^{*}$. It means that the fixedprice of R\&D outsourcing in the case of complementary relation is less than that in the case of substitutional relation. From the above comparisons, we can draw conclusion 1.

Conclusion 1: When the costs of explicit and tacit knowledge sharing are complementary, $\beta_{1}^{* *}>\beta_{1}^{*}, e_{1}^{* *}>e_{1}^{*}, e_{2}^{* *}>e_{2}^{*}, R^{* *}>R^{*}, F^{* *}<F^{*}$.

Conclusion 1 shows when the costs of explicit and tacit knowledge sharing are complementary, the buyer can increase the incentive coefficient of explicit knowledge sharing $\left(e_{2}^{* *}>e_{2}^{*}=0\right)$ to stimulate tacit knowledge sharing $\left(\beta_{1}^{* *}>\beta_{1}^{*}\right)$. This motive method not only stimulates tacit knowledge sharing, but also can further stimulate the effort levels of explicit knowledge sharing $\left(e_{1}^{* *}>e_{1}^{*}\right)$.

Through the analysis above, the parameters of the formal R\&D outsourcing contracts and the effort levels of explicit and tacit knowledge sharing in these contracts have been obtained. Then, is the design of these R\&D outsourcing contracts effective in stimulation? For this purpose, the effort levels of explicit and tacit knowledge sharing under centralized decision are given as benchmarks. Under centralized decision, the buyer and service providers are viewed as a system to make optimal decisions, then the sum of the revenues of the buyer and service providers is $R+r=\lambda_{1} e_{1}+\lambda_{2} e_{2}-\frac{1}{2}\left(k_{1} e_{1}^{2}+k_{2} e_{2}^{2}+s e_{1} e_{2}\right)$, and the optimal $e_{1}$ and $e_{2}$ are decided to maximize the total expected revenue. The resulted effort levels of explicit and tacit knowledge sharing under centralized decision $e_{1}^{J}$ and $e_{2}^{J}$ are as follows, $e_{1}^{J}=\frac{2 \lambda_{1}\left(2 k_{2}-s\right)}{4 k_{1} k_{2}-s^{2}}, e_{2}^{J}=\frac{2 \lambda_{1}\left(2 k_{2}-s\right)}{4 k_{1} k_{2}-s^{2}}$. When $s>0, e_{1}^{J}-e_{1}^{*}=\frac{2 \lambda_{1}\left(2 k_{2}-s\right)}{4 k_{1} k_{2}-s^{2}}-\frac{\lambda_{1}}{k_{1}}=\frac{2 \lambda_{1}\left(-2 k_{2}+s\right)}{\left(4 k_{1} k_{2}-s^{2}\right) k_{1}}$, obviously $e_{1}^{J}-e_{1}^{*}>0$. At the same time, when $e_{2}^{*}=0$, it is obviously that $e_{2}^{J}-e_{2}^{*}>0$. When $s<0, e_{1}^{J}-e_{1}^{* * *}=\frac{2 \lambda_{1}\left(2 k_{2}-s\right)}{4 k_{1} k_{2}-s^{2}}-\frac{2 \lambda_{1}\left(2 k_{2}-s\right)}{4 k_{1} k_{2}-s^{2}}=0$, 
$e_{2}^{J}-e_{2}^{* * *}=\frac{2 \lambda_{1}\left(2 k_{2}-s\right)}{4 k_{1} k_{2}-s^{2}}--\frac{\lambda_{1} s\left(2 k_{2}-s\right)}{k_{2}\left(4 k_{1} k_{2}-s^{2}\right)}=\frac{\lambda_{1}\left(2 k_{2}-s\right)\left(2 k_{2}+s\right)}{k_{2}\left(4 k_{1} k_{2}-s^{2}\right)}$. According to the assumptions above, it is obviously that $e_{2}^{J}-e_{2}^{* *}>0$.

Conclusion 2: when $s>0$, then $e_{1}^{J}>e_{1}^{*}, e_{2}^{J}>e_{2}^{*}$. When $s<0$, then $e_{1}^{J}=e_{1}^{* *}, e_{?}^{J}>e_{?}^{* *}$.

Conclusion 2 shows, when $s>0$, namely the effort costs of explicit and tacit knowledge sharing can substitute each other, formal R\&D outsourcing contracts cannot stimulate explicit and tacit knowledge sharing to be optimal. When $s<0$, namely the effort costs of explicit and tacit knowledge sharing are complementary, formal R\&D outsourcing contract can only stimulate explicit knowledge sharing to be optimal but fails to stimulate tacit knowledge sharing. That is to say, formal R\&D outsourcing contract has not realized optimal system and has room for Pareto improvement. For tacit knowledge sharing especially, there is considerable room for Pareto improvement.

\section{Conclusions}

$R \& D$ outsourcing has become one of the most effective ways for enterprises to acquire external knowledge rapidly. The existing researches focus on transferring and sharing explicit knowledge whose value can be verified, but ignore the transmission and sharing of tacit knowledge whose value cannot be unverified .Thus leading to the lack of tacit knowledge sharing in R\&D outsourcing. In order to stimulate tacit knowledge sharing as well as explicit knowledge sharing, a multitask principal-agent model of simultaneous stimulation of explicit and tacit knowledge is established and the incentive effects of formal and informal relational contracts on knowledge sharing are analyzed. Researches show that when the relationship between the costs of explicit and tacit knowledge sharing are mutually substitutable, formal contract can only stimulate the effort of sharing explicit knowledge but fails to stimulate the effort of sharing tacit knowledge. When the two are complementary, formal contract can stimulate the efforts of sharing explicit and tacit knowledge at the same time. However, it can only stimulate the effort of explicit knowledge sharing to the optimal level, not tacit knowledge sharing.

\section{Acknowledgments}

Our work was supported by Natural Science Foundation of China (Grants No. 71301182, 71172095), the Program for Basic and forward research in Chongqing (Grant No. cstc2013jcyjA0998), the Project of Scientific and Technological Research Program of Chongqing 
Municipal Education Commission (Grant No. KJ1400909), the Opening Funding of Chongqing Key Laboratory of Electronic Commerce \& Modern Logistics (Grant No. ECML201402), the National Social Science Fund of China (Grants No. 14BGL100), the Chongqing Science \& Technology Commission (Grants No. cstc2014jccxB60001), and educational commission of Shanxi province of china (Grants No. 14JK1065).

\section{References}

Aksin, O.Z., De Véricourt, F., \& Karaesmen, F. (2008). Call center outsourcing contract analysis and choice. Management Science, 54(2), 354-368. http://dx.doi.org/10.1287/mnsc.1070.0823

Bals, L., Kneis, K.C., Lemke, C., \& Pedersen, T. (2013). Toward a flexible breathing organization: r\&d outsourcing at bayer. Offshoring Challenge, 211-226. http://dx.doi.org/10.1007/978-1-4471-4908-8_12

Buss, P., \& Peukert, C. (2015). R\&D outsourcing and intellectual property infringement. Research Policy, 44, 977-989. http://dx.doi.org/10.1016/j.respol.2014.11.006

Cai, S., Kai, C., \& Zou, B. (2011). Producer services outsourcing risk control based on outsourcing contract design: industrial engineering perspective. Systems Engineering Procedia, 2, 308-315. http://dx.doi.org/10.1016/j.sepro.2011.10.043

Cheng, J.H. (2011). Inter-organizational relationships and knowledge sharing in green supply chains-Moderating by relational benefits and guanxi. Transportation Research Part E: Logistics and Transportation Review, 47(6), 837-849. http://dx.doi.org/10.1016/j.tre.2010.12.008

Gershman, M., \& Kuznetsova, T. (2013). Efficient Contract in the R\&D Sector: Key Parameters. Foresight-Russia, 7(3), 26-36. http://dx.doi.org/10.17323/1995-459x.2013.3.26.36

Han, S.Y., \& Bae, S.J. (2014). Internalization of R\&D outsourcing: An empirical study. International Journal of Production Economics, 150, 58-73. http://dx.doi.org/10.1016/j.ijpe.2013.12.001

Jain, N., Hasija, S., \& Popescu, D.G. (2013). Optimal contracts for outsourcing of repair and restoration services. Operations Research, 61(6), 1295-1311. http://dx.doi.org/10.1287/opre.2013.1210

Kloyer, M., \& Scholderer, J. (2012). Effective incomplete contracts and milestones in market-distant R\&D collaboration. Research Policy, 41(2), 346-357. http://dx.doi.org/10.1016/j.respol.2011.11.003 
Kultti, K., \& Takalo, T. (2000). Incomplete contracting in an R\&D project: the Micronas case. R\&D Management, 30(1), 67-77. http://dx.doi.org/10.1111/1467-9310.00158

Lai, E.L.C., Riezman, R., \& Wang, P. (2009). Outsourcing of innovation. Economic Theory, 38(3), 485-515. http://dx.doi.org/10.1007/s00199-007-0326-4

Martínez-Noya, A., \& García-Canal, E. (2011). Technological capabilities and the decision to outsource/outsource offshore R\&D services. International Business Review, 20(3), 264-277. http://dx.doi.org/10.1016/j.ibusrev.2011.01.008

Mulkay, M. (2014). Science and the Sociology of Knowledge. Routledge.

Pashupatimath, G.R., \& Ramakrishna, H. (2015). Global engineering offshore outsourcing-a literature review. International Journal of Business and Systems Research, 9(1), 32-48. http://dx.doi.org/10.1504/IJBSR.2015.066803

Qi, C., \& Chau, P.Y. (2012). Relationship, contract and IT outsourcing success: Evidence from two descriptive case studies. Decision Support Systems, 53(4), 859-869. http://dx.doi.org/10.1016/j.dss.2012.05.018

Quinn, J.B. \& Strategy, E.S. (2013). Strategic outsourcing: leveraging knowledge capabilities. Image, 34.

Soekijad, M., \& Andriessen, E. (2003). Conditions for knowledge sharing in competitive alliances. European Management Journal, 21(5), 578-587. http://dx.doi.org/10.1016/S02632373(03)00107-5

Song, H., Zhang, D-M., Li, Y-Y. (2012). The Incentive Mechanism of Tacit Knowledge Sharing under Unverified Value in R\&D Outsourcing. Science \& Technology Progress and Policy, 29(23), 51-154.

Suppiah, V., \& Sandhu, M.S. (2011). Organisational culture's influence on tacit knowledge-sharing behaviour. Journal of knowledge management, 15(3), 462-477. http://dx.doi.org/10.1108/13673271111137439

Ulset, S. (1996). R\&D outsourcing and contractual governance: An empirical study of commercial R\&D projects. Journal of Economic Behavior \& Organization, 30(1), 63-82. http://dx.doi.org/10.1016/S0167-2681(96)00842-6

Yao, T., Jiang, B., Young, S.T., \& Talluri, S. (2010). Outsourcing timing, contract selection, and negotiation. International Journal of Production Research, 48(2), 305-326. http://dx.doi.org/10.1080/00207540903174858 
Zhou, Z., Qu, H., \& Joyce, B. (2012). The study of risk warning and controlling of R\&D outsourcing: based on bp neural network. International Journal of Strategic Change Management, 4(3-4), 250-265. http://dx.doi.org/10.1504/IJSCM.2012.051848

Zhu, X., Li, H., \& Zheng, D. (2014). Optimal contract design for outsourcing: saving time and money. International Journal of Business and Systems Research, 8(3), 278-294. http://dx.doi.org/10.1504/IJBSR.2014.063936

Journal of Industrial Engineering and Management, 2015 (www.jiem.org)

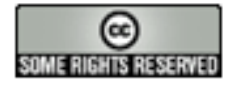

Article's contents are provided on an Attribution-Non Commercial 3.0 Creative commons license. Readers are allowed to copy, distribute and communicate article's contents, provided the author's and Journal of Industrial Engineering and Management's names are included. It must not be used for commercial purposes. To see the complete license contents, please visit http://creativecommons.org/licenses/by-nc/3.0/. 